\title{
LEARNING TO BE A PROFESSIONAL DESIGNER
}

\author{
Colin LEDSOME \\ Chair of Council, IED
}

\begin{abstract}
Part of the process of becoming a designer, in whatever field, is appreciating what it means to be part of a trusted community of designers. A professional approach to design is vital to maintaining the trust of our various marketplaces and the standard of our output. This paper is intended to show how fostering a professional attitude should be an important part of courses in both Product Design and Engineering. We each tend to see our own field of expertise as important, striving to achieve perfection in its application. However, when several areas of expertise are involved, each practitioner must have the flexibility to find the best compromise between them, so achieving an elegant solution to the total design challenge.
\end{abstract}

Keywords: Professionalism, compromise, teamwork

\section{INTRODUCTION}

Professionalism is one of those nebulous concepts, which you know what it is when you see it but find hard to define in any absolute terms. It implies a quality of behaviour, based on initial education and training followed by progressive experience leading to a reliable standard of competence. In most areas of activity, this is recognised by appropriate professional bodies, who set and maintain standards, which members are required to meet. In many countries, in many professions, this is a legally recognised qualification, but in the UK, there is no legal requirement for engineering or product designers to be registered professionals, except in certain activities where public safety is paramount.

A design professional is not just someone who gets paid to design. They should be relied upon to consider the needs of the market, the capacity and capability of the organisations involved and the available services and supplies within the industry in generating viable concepts for new products, then realising them at a cost acceptable to all stakeholders. They should also be able to identify the key challenges in taking a selected concept through to market and beyond. Nowadays this includes consideration of further use or disposal at the end of a life in service with minimum environmental impact [1].

All this is not something which can be learned purely in a classroom environment but requires practical experience of project work under time and cost constraints applying in as close as possible a simulation to an industrial context. What can be fostered, is an understanding of the importance of being professional and the desire to achieve it.

\section{THE PROFESSIONAL EXPECTATION}

The design of a new product can vary from the simple arrangement of existing components in a novel configuration, to the completely new artefact intended for some previously unattainable purpose. The first type includes, perhaps, an arrangement of available modules to fit out a kitchen in an ergonomic way. The latter may be the introduction of a new system for identifying and removing weeds from a lawn as it cuts the grass. In both cases, the user would expect the designer to have taken the care needed to consider their needs, even the ones they haven't thought of, to produce a design which will give them satisfaction in owning and using it.

The market should reasonably expect that the designer has been aware of any safety aspects, legal requirements or environmental impacts a product might have. A reasonable level of efficiency and effectiveness should be there in manufacture and use, within restrictions of price and material availability. The product should be a pleasure to use and own. We would probably express this as 
"quality", a term notoriously difficult to define [2]. We could philosophically define design as a search for quality.

\section{A PROFESSIONAL ATTITUDE}

A professional attitude in a designer develops slowly and the learning continues throughout a career. Initial academic learning provides a broad introduction to a number of concepts and makes some attempt to show the ways in which they can be useful. The latter part of a course often allows a student to concentrate on a more specific aspect of the whole field. This gives both an initial specialism in a future career and an exemplar of how to explore, and gain expertise in a particular topic. Some go on to specialise in that aspect, or a closely related one. Others use the learning experience to guide further learning in other fields to become a broader based thinker.

Both types of designer have a contribution to make to the design process. The specialist provides depth in particular areas, where a detailed insight gives clarity to aspects of the design, which may be fundamental to its acceptance by the user. The broader thinker provides the integrating capacity needed to discover a satisfactory product not dominated by any specific specialist concept. During this process it may be necessary for each specialist to accept a reduction in the perfection of their specific aspect in order to achieve the best total effect.

A student can gain some insight into this need for integration during group projects. However, they may well not appreciate it unless it is specifically pointed out as a retrospective review. Students usually gain more from their project work if they are guided to reflect on it as a learning experience relating the specific activities to more generally applicable principles. These principles can then be applied during further projects reinforcing the learning process.

For a young graduate in a design related field, it is worth considering the often-expressed opinion that the half-life of graduate level learning in a technical subject is about two and a half years. Underpinning knowledge and understanding gained in the early years of a degree is more fundamental and may change very slowly. Final year learning is often quite close to the latest research findings and so parts may be superseded within a short period. (In the 1950s, two new Comet 2 airliners broke up in flight and the resulting investigation completely changed our understanding of structural fatigue in a matter of months.) Since it is impossible to know which parts have been overtaken, practitioners should keep up with progress in areas of understanding outside their immediate experience, but within their field of interest. This is the wisdom of maintaining an attitude of continuing professional development, CPD, from the point of graduation right through a career.

Joining a professional body as a corporate member should be seen as recognition of having reached a standard of competence, which others may rely on. In many organisations, such a membership provides an external reassurance that a practitioner may be given higher levels of responsibility. It may be that no single professional body covers the whole range of activity of an individual.

In the engineering profession, a number of bodies have been established over the last two hundred years to cover different industries, areas of expertise and engineering tasks. Thus, an engineer could legitimately belong to at least three bodies, but rarely does. There are currently 36 bodies directly recognised by the Engineering Council and several more with some associated status. Some are specific to particular areas of industry, such as the Institution of Civil Engineers (originally named because they were non-military). Expertise bodies include the Institution of Mechanical Engineers, who have an interest wherever mechanisms are involved. The only current task orientated body is the Institution of Engineering Designers, although there was a separate Institution of Production Engineers, now swallowed by the Institution of Engineering and Technology. The current system grew up as historic needs were perceived, but perhaps could now be re-thought.

\section{THE ROLE OF PROFESSIONAL BODIES}

Becoming a member of a professional body helps foster a feeling of belonging to an extended team, keen to ensure that standards are maintained. It also gives exposure to other work, which broadens the understanding of their field and opens up new aspects of application. This in turn may lead to new links between topics, which can generate new concepts.

Senior members of a profession usually wish to pass on their expertise and learning to fellow members as well as those still gaining competence. They will publish information to members and perhaps have representation in organisations producing standards or codes of practice with impact in industries and businesses beyond their normal range of activity. 
Once qualified for membership, a young professional will be encouraged to contribute to the activities of the body by publishing information on the projects they work on, and by joining the committee structure which guides the activities. This helps career development by providing new experiences and helping to measure progress in their growing expertise. It may also reveal new opportunities by exposure to the work of others and the ways in which their industry is developing. It can also show where there are gaps in the available expertise leading to potential research opportunities and new types of product.

\section{FOSTERING AND MAINTAINING PROFESSIONALISM}

In 1991, a report, "Attaining Competence in Engineering Design" [3] included the following description of competence in professional responsibility, which is relevant across the whole design field:

"Chartered Engineers should:

- Have an attitude of responsibility towards the safety of user's colleagues, employers, and society.

- Possess personal integrity, a responsible attitude towards decisions, and pride in good practice.

- Never consent to incorporate features in a design, which mislead as to its true worth.

- Be familiar with standards and codes of behaviour acceptable to their professional bodies.

- Understand the need to maintain and develop expertise, both for their current task and their future career, by undertaking a programme of further study or training.

- Appreciate the historic and cultural development of relevant technologies and their relation to existing products and market expectations."

This description was intended to apply to practitioners at the time they reach a "chartered" level of competence. (Further work was proposed, to cover other types of engineering and design professionals, but the opportunity was never taken up).

Working towards, and then maintaining, this level of competence lies at the heart of professionalism. It can only be fully developed through practice, but seeds can be sown during initial academic qualification. Much can be done by introducing the concept of a profession, going beyond the vague aspect of a group of people with similar jobs, to the feeling of people working towards similar goals of performance helping each other along. Professional bodies do more than set accreditation standards. There may be events and publications relevant to the course as well as competitions and prize schemes specifically intended to encourage and develop students. This also helps link the students to the profession and give some understanding of the importance of their role.

\section{CONCLUSIONS}

In 2018, a UK designer and retailer of children's beds was given a jail sentence after a child became trapped in the gaps in the end of the bed and strangled. The judge decided to drop a charge of manslaughter. There is no record of the "designer" having a design qualification [4]. The importance of a professional attitude to design cannot be overemphasised.

I hope I have demonstrated that gaining a professional attitude is an important aim for a student designer and that the preparations for it can be encouraged during an initial academic course. Those teaching design bear some responsibility for the professional behaviour of their students, so should also maintain a familiarity with the application of the expertise they impart in the market places their graduates are likely to encounter.

\section{REFERENCES}

[1] BS8887 Design for manufacture, assembly, disassembly and end-of-life processing (MADE), British Standards Institution - ongoing series.

[2] Pirsig R.M. Zen and the Art of Motorcycle Maintenance - An Inquiry into Value”, 1974 and later editions.

[3] Attaining Competence in Engineering Design, the report of a joint Design Council/Engineering Council working party, The Design Council, 1991.

[4] Thomas T. Cot Tragedy and the Regulations. Engineering Designer, IED, March 2019.

In addition, professional bodies have Codes of Practice, to which they expect their members to adhere. These may well provide a useful reference in an academic course, when introducing the concept of professionalism. 